\title{
Potential benefits of garlic and other dietary supplements for the management of hypertension (Review)
}

\author{
TOSHIAKI MATSUTOMO \\ Central Research Institute, Wakunaga Pharmaceutical Co., Ltd., Akitakata-shi, Hiroshima 739-1195, Japan
}

Received August 8, 2019; Accepted September 12, 2019

DOI: $10.3892 /$ etm.2019.8375

\begin{abstract}
Elevated blood pressure is a major risk factor for cardiovascular diseases. Although some effective drug treatments are available, a relatively large proportion of patients have uncontrolled blood pressure. Dietary supplements are used for the prevention and treatment of hypertension as complementary and alternative medicines. Of the various dietary supplements, antioxidants, fish oil and diverse herbal products are commonly used. Within this context, it is important to determine the actual effectiveness and possible side-effects of these supplements; however, some of the products have been poorly investigated for their effects and safety. In the current review, we focus on garlic and several other dietary supplements, such as coenzyme Q10, fish oil and probiotics, that have exhibited significant beneficial effects on blood pressure in clinical trials. In addition, we discuss the possible mechanisms of action responsible for their anti-hypertensive effects, as well as the safety, active ingredients and their potential use as adjunct therapies for uncontrolled hypertension.
\end{abstract}

\section{Contents}

1. Introduction

2. Dietary supplements

3. Antioxidants and fish oil

4. Herbal products

5. Probiotics

6. Conclusion

\section{Introduction}

Hypertension is a major risk factor of cardiovascular diseases (CVD), which are the predominant cause of morbidity

Correspondence to: Dr Toshiaki Matsutomo, Central Research Institute, Wakunaga Pharmaceutical Co., Ltd., 1624 Shimokotachi, Koda-cho, Akitakata-shi, Hiroshima 739-1195, Japan

E-mail: matsutomo_t@wakunaga.co.jp

Key words: garlic, dietary supplements, hypertension, antioxidants, probiotics and mortality worldwide $(1,2)$. The treatment and control of hypertension are extremely important for the prevention of CVD and its related diseases (3). Generally, several types of drugs are recommended as first-line anti-hypertensive medications, including angiotensin-converting enzyme (ACE) inhibitors, angiotensin II receptor blockers (ARBs), dihydropyridine calcium channel blockers and thiazide diuretics $(4,5)$. When blood pressure cannot be controlled with one drug, treatment with multiple anti-hypertensive agents, such as combinations of ACE inhibitors or ARBs with dihydropyridine calcium channel blockers or thiazide diuretics is required (6). In spite of those well-established anti-hypertensive medications for high blood pressure, uncontrolled hypertension remains prevalent worldwide (7). In a cross-sectional study of 153,996 adults from 17 countries, more than half of the participants were unaware of their hypertension and blood pressure was controlled by the drug treatments in only $32.5 \%$ of the patients (8). The prevalence of uncontrolled hypertension in the United States decreased to approximately 50\% from 1999 to 2010, but it has since not been improved further (9). It is clear that uncontrolled hypertension should be treated by alternative means to prevent subsequent morbidity and mortality.

\section{Dietary supplements}

There has been a growing awareness of complementary and alternative approaches in the prevention and treatment of CVD. According to the 2012 National Health Interview Survey, the most popular healthcare approaches are natural products, which are widely marketed and are often sold as dietary supplements (10). Dietary supplements used for the management of hypertension include coenzyme Q10 (CoQ10), vitamins and minerals, fish oil and various herbal products (11). In addition, a recent review highlighted that manipulating the gut microbiota using probiotics may be a valuable adjuvant to traditional anti-hypertensive therapy (12). Although a large variety of dietary supplements are used worldwide, only a few products have been investigated extensively for their effectiveness, safety and potential interactions with other medicines and dietary supplements. Furthermore, food-based preparations contain a large number of constituents, the amounts of which may vary according to the raw material, the manufacturing process and several other factors. This type of complexity can cause the inconsistency between the results in different clinical studies. 
The use of the following dietary supplements has been reported to lead to a significant reduction in blood pressure without severe side-effects in multiple clinical trials (Table I).

\section{Antioxidants and fish oil}

Coenzyme Q10. CoQ10 is a potent antioxidant and an essential component of the mitochondrial electron transport chain (13). A number of studies have indicated that the plasma level of CoQ10 is associated with CVD, including hypertension and CoQ10 supplementation has been shown to be protective against such diseases $(14,15)$. In a 10 -week trial with hypertensive patients, systolic blood pressure (SBP) and diastolic blood pressure (DBP) were significantly reduced by $17.8 \mathrm{mmHg}$ and $12.0 \mathrm{mmHg}$, respectively (16). A randomized, double-blind study examining the anti-hypertensive effect of CoQ10 in patients with hypertension and coronary artery disease (CAD) demonstrated that SBP, DBP and heart rate were significantly decreased, and that the plasma levels of antioxidants, such as vitamins $\mathrm{A}$ and $\mathrm{E}$ were significantly increased after 8 weeks of treatment (17). Moreover, patients taking CoQ10 were able to reduce the dosage or the number of anti-hypertensive drugs in several studies $(15,17)$. The postulated principal mechanism underlying the beneficial effects of CoQ10 on hypertension is the decrease in peripheral resistance as a consequence of vasodilatation by preserving nitric oxide (NO) availability (18).

Clinical studies have indicated that CoQ10 treatment causes few adverse effects and minimal drug interactions. According to a meta-analysis by Rosenfeldt et al, side-effects were observed in only $0.8 \%$ in 12 studies with 3,500 patients (19). CoQ10 however, may increase the risk of bleeding in patients taking antiplatelet drugs due to its effect on platelet function (20). Overall, CoQ10 is a safe dietary supplement and can be a potent adjuvant for anti-hypertensives medication.

Vitamin C. Researchers have investigated the potential effects of vitamin $\mathrm{C}$ supplementation in the management of hypertension. The blood pressure-lowering effect of vitamin $\mathrm{C}$ was previously observed following treatment with $500 \mathrm{mg}$ daily for 4 to 6 weeks in patients with hypertension $(21,22)$. A meta-analysis including 29 clinical trials reported that vitamin C supplementation for 8 weeks on average reduced SBP and DBP by $3.8 \mathrm{mmHg}$ and $1.5 \mathrm{mmHg}$, respectively (23). Of note, a clinical study with 77 mostly normotensive participants suggested that the intravenous administration of high-dose vitamin C led to an acute reduction in blood pressure, particularly in prehypertensive patients (24). Furthermore, Mahajan et al reported that concomitant treatment with vitamin $\mathrm{C}$ and the anti-hypertensive drug, amlodipine, provided additional benefits, namely a lower SBP and higher serum level of superoxide dismutase (25). The anti-hypertensive effect of vitamin $\mathrm{C}$ is probably ascribed to the improvement of endothelial function by directly scavenging free radicals, which causes vascular damage in hypertensive patients. Padayatty et al surveyed 172 practitioners who administered vitamin $C$ to 20,109 patients and reported that the side-effects of vitamin $\mathrm{C}$ appeared to be relatively minor (26).

Fish oil. Fish oil contains long-chain and highly polyunsaturated n-3 fatty acids (n-3 PUFAs), such as eicosapentaenoic acid and docosahexaenoic acid. The consumption of fish oil or n-3 PUFAs is inversely associated with mortality from CVD $(27,28)$. The majority of clinical studies exploring the effects of fish oil on hypertensive participants indicated that fish oil intervention caused a modest, but significant reduction in both SBP and DBP $(29,30)$. Conversely, there was no effect on blood pressure in studies with normotensive subjects (31). A meta-analysis of 31 placebo-controlled trials concluded that the dose-dependent effect of fish oil on blood pressure was dependent on the treatment period and subject type (32). The consistent effect of fish oil can be manifested by a study design with hypertensive patients treated for more than 3 weeks. It has been reported that n-3 PUFAs induce endothelial NO synthase (eNOS) expression and activation, leading to endothelium-dependent vasorelaxation (33). In addition, n-3 PUFAs appear to have a variety of beneficial effects on cardiometabolic risk factors, such as blood lipid levels, platelet function and inflammatory markers (34). To date, at least to the best of our knowledge, there are no studies available reporting the adverse effects of fish oil supplementation.

\section{Herbal products}

Ginseng. Ginseng is one of the most commonly used herbal products for the prevention and treatment of hypertension. This herb has been reported to exert beneficial effects on atherosclerosis and CVD, as well as hypertension $(35,36)$. Jovanovski et al demonstrated that Korean red ginseng (Panax Ginseng), rich in ginsenoside $\operatorname{Rg} 3$, acutely decreased central and peripheral blood pressure in 23 young, healthy individuals (35). Significant reductions were observed in central SBP and DBP (-5.7 $\mathrm{mmHg}$ and $-5.1 \mathrm{mmHg}$, respectively), as well as the augmentation index (-4.3\%) at $3 \mathrm{~h}$ following the administration of a $400 \mathrm{mg}$ dose. American ginseng (Panax quinquefolius), another major form of ginseng, has been shown to significantly decrease SBP by $11.7 \%$ and arterial stiffness by $5.3 \%$ in 64 individuals with essential hypertension and type 2 diabetes receiving $3 \mathrm{~g}$ of ginseng extract for 12 weeks (36). The main active components of ginseng are considered to be ginsenosides, which have been reported to exert beneficial effects on the cardiovascular system $(37,38)$. As regards the mode of action, the improvement of vascular function by ginseng has been attributed to the increase in the production of NO through the eNOS-dependent mechanism $(36,39)$. By contrast, others have concluded that ginseng does not affect either arterial stiffness or blood pressure in subjects with hypertension (40). These inconsistent results may be due to the differences in the ginsenoside concentrations in ginseng preparations, the study population and the measurement methods. Systematic reviews evaluating the safety have concluded that ginseng has a good safety profile with no specific adverse events $(39,41)$.

Garlic. Garlic (Allium sativum) has been used globally since ancient times for its diverse effects, and in particular for its cardioprotective properties, including its blood pressure-lowering effects. The findings from different meta-analyses of clinical studies on the anti-hypertensive effects of garlic are inconsistent (42-44); however, the most recently published analysis indicated that garlic supplements are effective for subjects 


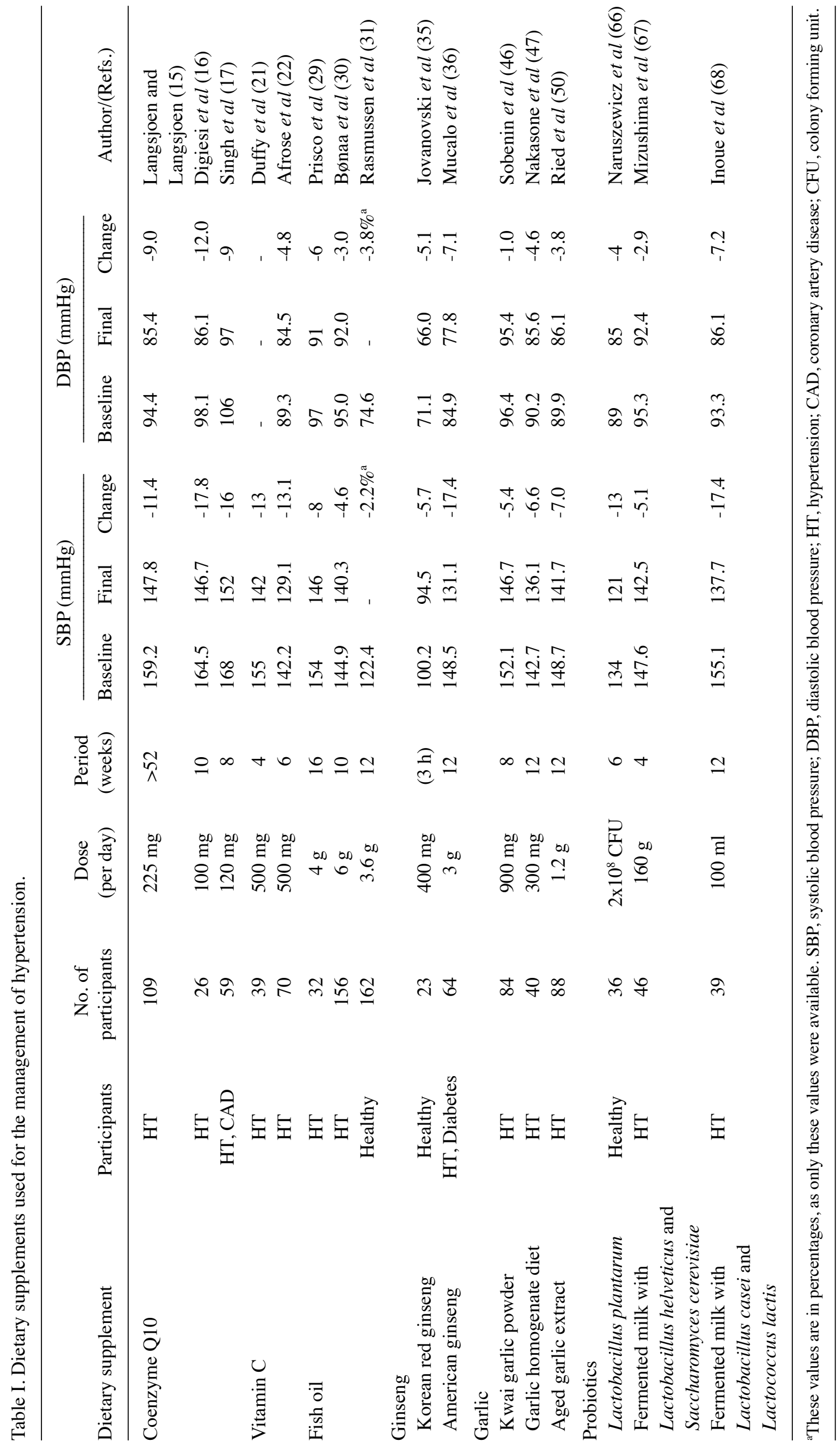


with hypertension and slightly elevated cholesterol levels (45). More than 10 studies performed using Kwai garlic powder have suggested that garlic supplement in doses ranging from 600 to $900 \mathrm{mg} /$ day exert potent effects on blood pressure in hypertensive individuals, but not in normotensive individuals (46). Likewise, in the clinical study by Nakasone et al, treatment with a garlic homogenate-based supplementary diet for 12 weeks resulted in a significant reduction in both SBP and DBP only in patients with hypertension (47). The most consistent effects were observed in studies using aged garlic extract (AGE), another garlic preparation produced through natural aging for $>10$ months (48). AGE has been shown to significantly reduce blood pressure in patients with uncontrolled hypertension, suggesting that it may be used as a potent adjunct therapy for uncontrolled hypertension (49,50). Intriguingly, Ried et al demonstrated that AGE lowered arterial stiffness, decreased inflammation and improved gut microbiota beneficially for cardiovascular health (51). AGE has also been shown to improve peripheral circulation in hypertensive rats, increase the plasma level of NO in mice and induce endothelium-dependent vasorelaxation of isolated rat aortic rings (52-54).

Allicin has been considered as a major active ingredient in garlic supplementation, since it has been reported to exert angiotensin II-inhibiting and vasodilating effects $(55,56)$. In addition to allicin, $\gamma$-glutamyl- $S$-allylcysteine (GSAC) may contribute to the effects by inhibiting ACE and inducing endothelium-dependent and -independent relaxation (47). In AGE, allicin and GSAC are chemically converted to other sulfur compounds including $S$-allylcysteine (SAC) and $S$-1-propenylcysteine (S1PC) during the aging process. SAC has been shown to reduce renal injury and hypertension in 5/6 nephrectomized rats, which was shown to be associated with its antioxidant properties (57). Both the single and repeated administration of S1PC have been shown to significantly lower blood pressure in hypertensive rats by modulating various regulatory molecules, such as histidine, tryptophan and lyso-phosphatidylcholine $(58,59)$. The anti-hypertensive mechanisms of AGE appear to be divergent due to its various active ingredients.

The majority of studies have stated that garlic supplements are very safe. Only a few studies have reported that the use of garlic may cause adverse events, such as malodorous breath, body odor and mild gastrointestinal disturbances $(60,61)$. These side-effects are prominently observed in studies using raw garlic and are alleviated in interventions with AGE (62).

\section{Probiotics}

Recently, probiotics have attracted considerable interest for their health promoting benefits, including the management of blood pressure $(12,63)$. Gut microbial richness and diversity have been shown to be markedly reduced both in animal and human hypertension and this microbiota dysbiosis contributes to the pathogenesis of hypertension $(64,65)$. A growing number of clinical trials have reported that the use of probiotics leads to a moderate or significant reduction in blood pressure, which is associated with the improvement of the gut microbiota (63). For example, the intake of a drink containing Lactobacillus plantarum for 6 weeks has been shown to lead to a significant reduction in SBP, leptin, fibrinogen and interleukin-6 in healthy participants (66). In several studies with hypertensive subjects, milk fermented with bacteria, in particular the Lactobacillus species, has been shown to significantly decrease blood pressure $(67,68)$. The study by Aoyagi et al suggested that the consumption of fermented milk products containing Lactobacillus casei at least 3 times a week considerably reduced the incidence of hypertension over a 5-year follow-up period (69). In a comparative study between bacteria, a yoghurt product fermented with one strain of Enterococcus faecium and two strains of Streptococcus thermophilus more significantly reduced low-density lipoprotein cholesterol and blood pressure than that fermented with less strains or other bacteria in obese participants (70).

It has been demonstrated that probiotics improve lipid levels, reduce blood glucose levels and regulate the renin-angiotensin system, which contributes to the decrease in blood pressure (71-73). In addition, Tanida et al demonstrated that the intraduodenal injection of Lactobacilli or its metabolites reduced hypertension and renal sympathetic nerve activity via the central histaminergic system in urethane-anesthetized rats (74). These findings suggest that the anti-hypertensive effects of probiotics are associated with several different mechanisms. No side-effects have been reported in clinical studies to date, at least to the best of our knowledge.

\section{Conclusion}

A number of dietary supplements are available and are used as anti-hypertensive medication worldwide; however, not all the products have been extensively studied in terms of their effects on blood pressure or for any adverse effects. The present review provides an overview of dietary supplements recommended for the prevention and treatment of hypertension from the viewpoint of substantial benefits with minor or no side-effects in clinical studies. Notably, a few garlic preparations and probiotic products can reduce blood pressure by multiple mechanisms. In addition, they have demonstrated various health-promoting properties both in animal and human studies, suggesting that they may be used as beneficial complementary and alternative medications in hypertension therapy. There is still controversy on the association between the supplementation of some products and blood pressure since clinical studies have reported inconsistent conclusions, probably due to the differences in study designs. Larger and longer term trials and cross-sectional analyses are required to determine the substantial benefits and risks associated with the use of these dietary supplements.

\section{Acknowledgements}

The author would like to thank Dr Takami Oka of Wakunaga Pharmaceutical Co., Ltd. for his helpful advice, his encouragement and his critical reading of the manuscript.

\section{Funding}

No funding was received.

\section{Availability of data and materials}

Not applicable. 


\section{Authors' contributions}

TM researched the literature, performed the analysis of the data and drafted the manuscript. The author has read and approved the final manuscript.

\section{Ethics approval and consent to participate}

Not applicable.

\section{Patient consent for publication}

Not applicable.

\section{Competing interests}

The author declares that there are no competing interests.

\section{References}

1. GBD 2013 Risk Factors Collaborators, Forouzanfar MH, Alexander L, Anderson HR, Bachman VF, Biryukov S, Brauer M, Burnett R, Casey D, Coates MM, et al: Global, regional, and national comparative risk assessment of 79 behavioural, environmental and occupational, and metabolic risk factors or clusters of risks in 188 countries, 1990-2013: A systematic analysis for the Global Burden of Disease Study 2013. Lancet 386: 2287-2323, 2015.

2. Kearney PM, Whelton M, Reynolds K, Muntner P, Whelton PK and He J: Global burden of hypertension: Analysis of worldwide data. Lancet 365: 217-223, 2005

3. Lafeber M, Spiering W, Visseren FL and Grobbee DE: Multifactorial prevention of cardiovascular disease in patients with hypertension: The cardiovascular polypill. Curr Hypertens Rep 18: 40, 2016.

4. Park C, Wang G, Durthaler JM and Fang J: Cost-effectiveness analyses of antihypertensive medicines: A systematic review. Am J Prev Med 53: S131-S142, 2017.

5. Garjón J, Saiz LC, Azparren A, Elizondo JJ, Gaminde I, Ariz MJ, Erviti J and Erviti J: First-line combination therapy versus first-line monotherapy for primary hypertension. Cochrane Database Syst Rev 1: CD010316, 2017.

6. Oparil S, Acelajado MC, Bakris GL, Berlowitz DR, Cífková R, Dominiczak AF, Grassi G, Jordan J, Poulter NR, Rodgers A, et al: Hypertension. Nat Rev Dis Primers 4: 18014, 2018.

7. Cho J, Kim C, Kang DR and Park JB: Hyperuricemia and uncontrolled hypertension in treated hypertensive patients: K-MetS Study. Medicine (Baltimore) 95: e4177, 2016.

8. Chow CK, Teo KK, Rangarajan S, Islam S, Gupta R, Avezum A, Bahonar A, Chifamba J, Dagenais G, Diaz R, et al; PURE (Prospective Urban Rural Epidemiology) Study investigators: Prevalence, awareness, treatment, and control of hypertension in rural and urban communities in high-, middle-, and low-income countries. JAMA 310: 959-968, 2013.

9. FryarCD, Ostchega Y,Hales CM,Zhang G and Kruszon-Moran D: Hypertension prevalence and control among adults: United States, 2015-2016. NCHS Data Brief 289: 1-8, 2017.

10. National Institutes of Health (NIH): National Center for Complementary and Integrative Health (NCCIH): Complementary, Alternative, or Integrative Health: What's In a Name? https://nccih. nih.gov/health/integrative-health.

11. Afolayan AJ and Wintola OA: Dietary supplements in the management of hypertension and diabetes - a review. Afr J Tradit Complement Altern Med 11: 248-258, 2014.

12. Upadrasta A and Madempudi RS: Probiotics and blood pressure: Current insights. Integr Blood Press Control 9: 33-42, 2016.

13. Santos-Ocaña C, Do TQ, Padilla S, Navas P and Clarke CF: Uptake of exogenous coenzyme $\mathrm{Q}$ and transport to mitochondria is required for bcl complex stability in yeast coq mutants. J Biol Chem 277: 10973-10981, 2002.

14. Yamagami T, Shibata N and Folkers $\mathrm{K}$ : Bioenergetics in clinical medicine. Studies on coenzyme Q10 and essential hypertension. Res Commun Chem Pathol Pharmacol 11: 273-288, 1975.
15. Langsjoen $\mathrm{PH}$ and Langsjoen AM: Overview of the use of CoQ10 in cardiovascular disease. Biofactors 9: 273-284, 1999.

16. Digiesi V, Cantini F, Oradei A, Bisi G, Guarino GC, Brocchi A, Bellandi F, Mancini M and Littarru GP: Coenzyme Q10 in essential hypertension. Mol Aspects Med 15 (Suppl 1): s257-s263, 1994.

17. Singh RB, Niaz MA, Rastogi SS, Shukla PK and Thakur AS: Effect of hydrosoluble coenzyme Q10 on blood pressures and insulin resistance in hypertensive patients with coronary artery disease. J Hum Hypertens 13: 203-208, 1999.

18. Pepe S, Marasco SF, Haas SJ, Sheeran FL, Krum H and Rosenfeldt FL: Coenzyme Q10 in cardiovascular disease. Mitochondrion 7 (Suppl): S154-S167, 2007.

19. Rosenfeldt FL, Haas SJ, Krum H, Hadj A, Ng K, Leong JY and Watts GF: Coenzyme Q10 in the treatment of hypertension: A meta-analysis of the clinical trials. J Hum Hypertens 21: 297-306, 2007.

20. Serebruany VL, Ordonez JV, Herzog WR, Rohde M, Mortensen SA, Folkers K and Gurbel PA: Dietary coenzyme Q10 supplementation alters platelet size and inhibits human vitronectin (CD51/CD61) receptor expression. J Cardiovasc Pharmacol 29: 16-22, 1997.

21. Duffy SJ, Gokce N, Holbrook M, Huang A, Frei B, Keaney JF Jr and Vita JA: Treatment of hypertension with ascorbic acid. Lancet 354: 2048-2049, 1999.

22. Afrose SA, Fahmeed A, Mujtaba A, Khan M and Noorulla SM: A study on effects of combining vitamin $C$ with hypertension therapy. Int J Pharm Res Allied Sci 4: 142-146, 2015.

23. Juraschek SP, Guallar E, Appel LJ and Miller ER III: Effects of vitamin C supplementation on blood pressure: A meta-analysis of randomized controlled trials. Am J Clin Nutr 95: 1079-1088, 2012

24. Ried K, Travica N and Sali A: The acute effect of high-dose intravenous vitamin $\mathrm{C}$ and other nutrients on blood pressure: A cohort study. Blood Press Monit 21: 160-167, 2016.

25. Mahajan AS, Babbar R, Kansal N, Agarwal SK and Ray PC: Antihypertensive and antioxidant action of amlodipine and vitamin $\mathrm{C}$ in patients of essential hypertension. J Clin Biochem Nutr 40: 141-147, 2007.

26. Padayatty SJ, Sun AY, Chen Q, Espey MG, Drisko J and Levine M: Vitamin C: Intravenous use by complementary and alternative medicine practitioners and adverse effects. PLoS One 5: e11414, 2010.

27. Connor SL and Connor WE: Are fish oils beneficial in the prevention and treatment of coronary artery disease? Am J Clin Nutr 66 (Suppl 4): 1020S-1031S, 1997.

28. Simopoulos AP: Omega-3 fatty acids in health and disease and in growth and development. Am J Clin Nutr 54: 438-463, 1991.

29. Prisco D, Paniccia R, Bandinelli B, Filippini M, Francalanci I, Giusti B, Giurlani L, Gensini GF, Abbate R and Neri Serneri GG: Effect of medium-term supplementation with a moderate dose of $\mathrm{n}-3$ polyunsaturated fatty acids on blood pressure in mild hypertensive patients. Thromb Res 91: 105-112, 1998.

30. Bønaa KH, Bjerve KS, Straume B, Gram IT and Thelle D: Effect of eicosapentaenoic and docosahexaenoic acids on blood pressure in hypertension. A population-based intervention trial from the Troms $\varnothing$ study. N Engl J Med 322: 795-801, 1990.

31. Rasmussen BM, Vessby B, Uusitupa M, Berglund L, Pedersen E, Riccardi G, Rivellese AA, Tapsell L and Hermansen K; KANWU Study Group: Effects of dietary saturated, monounsaturated, and n-3 fatty acids on blood pressure in healthy subjects. Am J Clin Nutr 83: 221-226, 2006.

32. Morris MC, Sacks F and Rosner B: Does fish oil lower blood pressure? A meta-analysis of controlled trials. Circulation 88 : 523-533, 1993.

33. Yagi S, Fukuda D, Aihara KI, Akaike M, Shimabukuro M and Sata M: n-3 Polyunsaturated fatty acids: Promising nutrients for preventing cardiovascular disease. J Atheroscler Thromb 24 . 999-1010, 2017.

34. Innes JK and Calder PC: The differential effects of eicosapentaenoic acid and docosahexaenoic acid on cardiometabolic risk factors: A systematic review. Int J Mol Sci 19: E532, 2018.

35. Jovanovski E, Bateman EA, Bhardwaj J, Fairgrieve C, Mucalo I, Jenkins AL and Vuksan V: Effect of Rg3-enriched Korean red ginseng (Panax ginseng) on arterial stiffness and blood pressure in healthy individuals: A randomized controlled trial. J Am Soc Hypertens 8: 537-541, 2014.

36. Mucalo I, Jovanovski E, Rahelić D, Božikov V, Romić Z and Vuksan V: Effect of American ginseng (Panax quinquefolius $\mathrm{L}$.) on arterial stiffness in subjects with type-2 diabetes and concomitant hypertension. J Ethnopharmacol 150: 148-153, 2013. 
37. Kim JH: Cardiovascular diseases and Panax ginseng: A review on molecular mechanisms and medical applications. J Ginseng Res 36: 16-26, 2012.

38. Chen H, Yin J, Deng Y, Yang M, Xu L, Teng F, Li D, Cheng Y, Liu S, Wang D, et al: The protective effects of ginsenoside Rg1 against hypertension target-organ damage in spontaneously hypertensive rats. BMC Complement Altern Med 12: 53, 2012.

39. Lee NH and Son CG: Systematic review of randomized controlled trials evaluating the efficacy and safety of ginseng. J Acupunct Meridian Stud 4: 85-97, 2011.

40. Stavro PM, Woo M, Heim TF, Leiter LA and Vuksan V: North American ginseng exerts a neutral effect on blood pressure in individuals with hypertension. Hypertension 46: 406-411, 2005.

41. Kim YS, Woo JY, Han CK and Chang IM: Safety analysis of Panax ginseng in randomized clinical trials: A systematic review. Medicines (Basel) 2: 106-126, 2015.

42. Reinhart KM, Coleman CI, Teevan C, Vachhani P and White CM: Effects of garlic on blood pressure in patients with and without systolic hypertension: A meta-analysis. Ann Pharmacother 42: 1766-1771, 2008

43. Ried K, Frank OR, Stocks NP, Fakler P and Sullivan T: Effect of garlic on blood pressure: A systematic review and meta-analysis. BMC Cardiovasc Disord 8: 13, 2008.

44. Wang HP, Yang J, Qin LQ and Yang XJ: Effect of garlic on blood pressure: A meta-analysis. J Clin Hypertens (Greenwich) 17: 223-231, 2015.

45. Ried K: Garlic lowers blood pressure in hypertensive individuals, regulates serum cholesterol, and stimulates immunity: An updated meta-analysis and review. J Nutr 146: 389S-396S, 2016.

46. Sobenin IA, Andrianova IV, Fomchenkov IV, Gorchakova TV and Orekhov AN: Time-released garlic powder tablets lower systolic and diastolic blood pressure in men with mild and moderate arterial hypertension. Hypertens Res 32: 433-437, 2009.

47. Nakasone $Y$, Nakamura Y, Yamamoto $T$ and Yamaguchi $H$ : Effect of a traditional Japanese garlic preparation on blood pressure in prehypertensive and mildly hypertensive adults. Exp Ther Med 5: 399-405, 2013.

48. United States Pharmacopeial Convention I. United States Pharmacopoeia 38 Garlic Fluid Extract USP 28-NF 33. United States Pharmacopeial Convention, Rockville, MD, pp6052-6055, 2015.

49. Ried K, Frank OR and Stocks NP: Aged garlic extract reduces blood pressure in hypertensives: A dose-response trial. Eur J Clin Nutr 67: 64-70, 2013.

50. Ried K, Travica N and Sali A: The effect of aged garlic extract on blood pressure and other cardiovascular risk factors in uncontrolled hypertensives: The AGE at heart trial. Integr Blood Press Control 9: 9-21, 2016

51. Ried K, Travica N and Sali A: The effect of Kyolic aged garlic extract on gut microbiota, inflammation, and cardiovascular markers in hypertensives: The GarGIC trial. Front Nutr 5: 122, 2018.

52. Ushijima M, Takashima M, Kunimura K, Kodera Y, Morihara N and Tamura K: Effects of S-1-propenylcysteine, a sulfur compound in aged garlic extract, on blood pressure and peripheral circulation in spontaneously hypertensive rats. J Pharm Pharmacol 70: $559-565,2018$

53. Morihara N, Sumioka I, Moriguchi T, Uda N and Kyo E: Aged garlic extract enhances production of nitric oxide. Life Sci 71: 509-517, 2002

54. Takashima M, Kanamori Y, Kodera Y, Morihara N and Tamura K: Aged garlic extract exerts endothelium-dependent vasorelaxant effect on rat aorta by increasing nitric oxide production. Phy tomedicine 24: 56-61, 2017.

55. Benavides GA, Squadrito GL, Mills RW, Patel HD, Isbell TS, Patel RP, Darley-Usmar VM, Doeller JE and Kraus DW: Hydrogen sulfide mediates the vasoactivity of garlic. Proc Natl Acad Sci USA 104: 17977-17982, 2007.

56. Mohamadi A, Jarrell ST, Shi SJ, Andrawis NS, Myers A Clouatre D and Preuss HG: Effects of wild versus cultivated garlic on blood pressure and other parameters in hypertensive rats. Heart Dis 2: 3-9, 2000.
57. Cruz C, Correa-Rotter R, Sánchez-González DJ, Hernández-Pando R, Maldonado PD, Martínez-Martínez CM, Medina-Campos ON, Tapia E, Aguilar D, Chirino YI, et al: Renoprotective and antihypertensive effects of S-allylcysteine in 5/6 nephrectomized rats. Am J Physiol Renal Physiol 293 F1691-F1698, 2007.

58. Matsutomo T, Ushijima M, Kunimura $\mathrm{K}$ and Ohtani $\mathrm{M}$ : Metabolomic study reveals the acute hypotensive effect of S-1-propenylcysteine accompanied by alteration of the plasma histidine level in spontaneously hypertensive rats. J Pharm Biomed Anal 168: 148-154, 2019.

59. Matsutomo $T$, Ushijima $M$, Kodera $Y$, Nakamoto $M$, Takashima M, Morihara N and Tamura K: Metabolomic study on the antihypertensive effect of S-1-propenylcysteine in spontaneously hypertensive rats using liquid chromatography coupled with quadrupole-Orbitrap mass spectrometry. J Chromatogr B Analyt Technol Biomed Life Sci 1046: 147-155, 2017.

60. Ackermann RT, Mulrow CD, Ramirez G, Gardner CD, Morbidoni L and Lawrence VA: Garlic shows promise for improving some cardiovascular risk factors. Arch Intern Med 161: 813-824, 2001.

61. Borrelli F, Capasso R and Izzo AA: Garlic (Allium sativum L.) Adverse effects and drug interactions in humans. Mol Nutr Food Res 51: 1386-1397, 2007.

62. Varshney R and Budoff MJ: Garlic and Heart Disease. J Nutr 146: 416S-421S, 2016.

63. Qi Y, Kim S, Richards EM, Raizada MK and Pepine CJ: Gut microbiota: Potential for a unifying hypothesis for prevention and treatment of hypertension. Circ Res 120: 1724-1726, 2017.

64. Yang T, Santisteban MM,Rodriguez V,Li E, Ahmari N,Carvajal JM, Zadeh M, Gong M, Qi Y,Zubcevic J, et al: Gut dysbiosis is linked to hypertension. Hypertension 65: 1331-1340, 2015.

65. Li J, Zhao F, Wang Y, Chen J, Tao J, Tian G, Wu S, Liu W, Cui Q, Geng B, et al: Gut microbiota dysbiosis contributes to the development of hypertension. Microbiome 5: 14, 2017.

66. Naruszewicz M, Johansson ML, Zapolska-Downar D and Bukowska H: Effect of Lactobacillus plantarum 299v on cardiovascular disease risk factors in smokers. Microbiome 5: 14, 2017.

67. Mizushima S, Ohshige K, Watanabe J, Kimura M, Kadowaki T, Nakamura Y, Tochikubo $\mathrm{O}$ and Ueshima H: Randomized controlled trial of sour milk on blood pressure in borderline hypertensive men. Am J Hypertens 17: 701-706, 2004

68. Inoue K, Shirai T, Ochiai H, Kasao M, Hayakawa K, Kimura M and Sansawa H: Blood-pressure-lowering effect of a novel fermented milk containing gamma-aminobutyric acid (GABA) in mild hypertensives. Eur J Clin Nutr 57: 490-495, 2003.

69. Aoyagi Y, Park S, Matsubara S, Honda Y, Amamoto R, Kushiro A, Miyazaki K and Shephard RJ: Habitual intake of fermented milk products containing Lactobacillus casei strain Shirota and a reduced risk of hypertension in older people. Benef Microbes 8: 23-29, 2017.

70. Agerholm-Larsen L, Raben A, Haulrik N, Hansen AS, Manders $M$ and Astrup A: Effect of 8 week intake of probiotic milk products on risk factors for cardiovascular diseases. Eur J Clin Nutr 54: 288-297, 2000.

71. Tabuchi M, Ozaki M, Tamura A, Yamada N, Ishida T, Hosoda M and Hosono A: Antidiabetic effect of Lactobacillus GG in streptozotocin-induced diabetic rats. Biosci Biotechnol Biochem 67: 1421-1424, 2003

72. Seppo L, Jauhiainen T, Poussa T and Korpela R: A fermented milk high in bioactive peptides has a blood pressure-lowering effect in hypertensive subjects. Am J Clin Nutr 77: 326-330, 2003.

73. Khalesi S, Sun J, Buys N and Jayasinghe R: Effect of probiotics on blood pressure: A systematic review and meta-analysis of randomized, controlled trials. Hypertension 64: 897-903, 2014.

74. Tanida M, Yamano T, Maeda K, Okumura N, Fukushima Y and Nagai K: Effects of intraduodenal injection of Lactobacillus johnsonii Lal on renal sympathetic nerve activity and blood pressure in urethane-anesthetized rats. Neurosci Lett 389: $109-114,2005$

This work is licensed under a Creative Commons Attribution-NonCommercial-NoDerivatives 4.0 International (CC BY-NC-ND 4.0) License. 